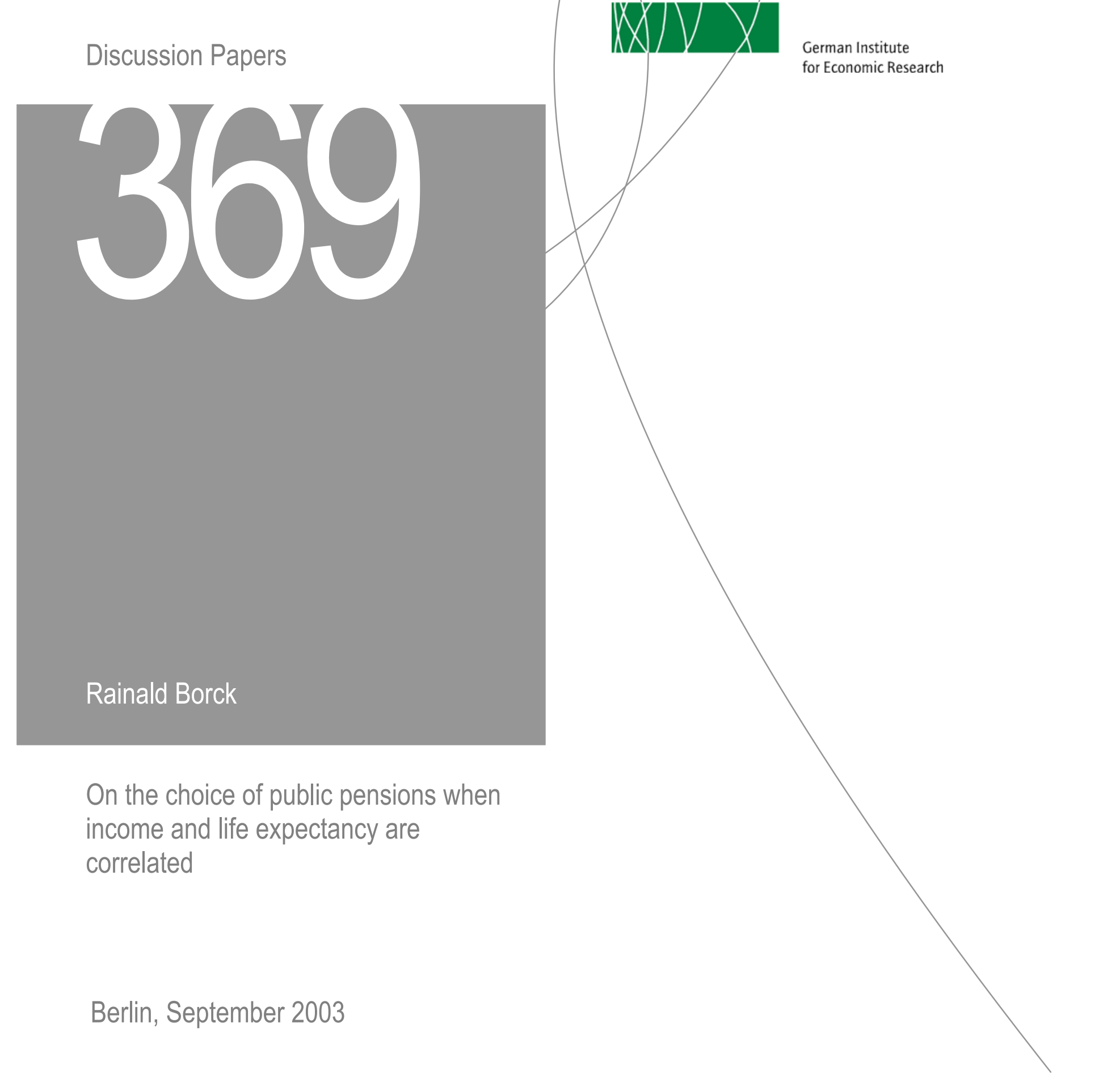


Opinions expressed in this paper are those of the author and do not necessarily reflect views of the Institute.

DIW Berlin

German Institute

for Economic Research

Königin-Luise-Str. 5

14195 Berlin,

Germany

Phone +49-30-897 89-0

Fax $\quad+49-30-89789-200$

www.diw.de

ISSN 1619-4535 


\title{
On the choice of public pensions when income and life expectancy are correlated
}

\author{
Rainald Borck*
}

DIW Berlin

September 18, 2003

\begin{abstract}
The paper presents a model where public pensions are determined by majority voting. Voters differ by age and income. Moreover, life expectancy increases with income. Depending on the strength of the link between contributions and benefits, and the relationship between income and life expectancy, individually optimal tax rates may increase or decrease with income. If they decrease, high tax rates are supported by pensioners and poor workers. If they increase with income, the coalition for high tax rates consists of pensioners and rich workers. 'Ends against the middle' equilibria are also possible.

JEL classification: H55, D72
\end{abstract}

Keywords: Voting, public pensions, life expectancy.

*Address: DIW Berlin, 14191 Berlin, Germany, Tel.: +49-30-89789-166, Fax: +49-30-89789-114, Email: rborck@diw.de. I would like to thank Pio Baake, Friedrich Breyer, Hermann Buslei, Allessandra Casarico, Panu Poutvaara, Matthias Wrede, Katharina Wrohlich, and seminar participants at DIW, the European Public Choice meeting in Aarhus, and the IIPF meeting in Prague for helpful comments. 


\section{Introduction}

Social spending has grown rapidly in industrial democracies, and a large part of this increase has been in old age pension systems. ${ }^{1}$ Understanding the reasons for this increase is therefore of great importance. Demographics are an obvious candidate for an explanation. Decreasing fertility and increasing life expectancy have led to an increasing political weight of pensioners.

The role played by intergenerational redistribution lies at the heart of many of the early contributions to the political economy of pensions (for a survey, see Galasso and Profeta, 2002). Following Browning (1975), much of the literature assumed that pensions are the outcome of a voting game where individuals differ by age only (e.g., Boadway and Wildasin, 1989). A natural implication is that pensions are determined by the voter with the median age. Browning (1975) argued that the social security budget is too large in a democracy, since the old and middle aged favor higher pensions than the young, but only the young internalize all the benefits and costs of pensions. ${ }^{2}$

However, as pension benefits are usually not perfectly tied down by contributions, pension systems redistribute within as well as between generations. Tabellini (2000) and Persson and Tabellini (2000) study models which allow for redistribution between voters who differ by income. Persson and Tabellini (2000) show that if benefits are unrelated to contributions, a coalition of old and poor young voters favoring high pensions is opposed by a coalition of rich young voters who favor low or zero pensions. With three generations, there are two decisive voters, a young and a middle aged one, where the young decisive

\footnotetext{
${ }^{1}$ This paper is exclusively concerned with unfunded or pay-as-you-go pension systems.

${ }^{2} \mathrm{~A}$ related argument is brought fourth by Mulligan and Sala-i-Martin (1999) who study a lobbying model of pension provision. Since the old do not work, their opportunity cost of lobbying is lower than that of workers, which may explain why the old are politically more powerful than mere numbers would suggest.
} 
voter has lower income than the middle aged one. See also Tabellini (2000) and Razin, Sadka and Swagel (2002) for similar models. Since the individually optimal tax rate of the decisive voters decreases with their income and increases with average income, the models predict that more inequality (appropriately measured) should lead to higher pensions. Yet the empirical support for this hypothesis is mixed (Lindert, 1996; Perotti, 1996; Tabellini, 2000; Razin et al., 2002). Therefore, new theoretical models which reexamine the link between income inequality and pension levels seem to be warranted.

Persson and Tabellini (2000) and Tabellini (2000) assume a Beveridgean pension system, where the individual benefits are not related to individual contributions. Yet many countries have pension systems where benefits do depend on contributions. Casamatta, Crémer and Pestieau (2000b) study a system which can be a combination of Beveridgean and Bismarckian, where in the latter benefits are determined by one's own contributions. ${ }^{3}$ They show that when the elasticity of intertemporal substitution is low, the individually optimal pension level increases with income until some level $\hat{w}$, above which the optimal pension is zero. The decisive voter has income $\tilde{w}<\hat{w}$, and all individuals with $\tilde{w}<w<\hat{w}$ prefer higher pensions and all those with $w<\tilde{w}$ or $w>\hat{w}$ lower pensions.

This paper analyzes another dimension of individual heterogeneity which influences the distributional conflict over pensions, namely, differing life expectancies. Since the individual pension is paid out as an annuity regardless of one's life span, the pension system redistributes from individuals with short life expectancy to those who live longer. For instance, for a given earnings history typical pension systems redistribute from men to women, since women live longer on average. Furthermore, since wealthier individuals tend to live longer, the intragenerational redistribution implied by public pension systems is reduced. Interestingly, while the importance of ageing for social security is recognized

\footnotetext{
${ }^{3}$ Casamatta, Crémer and Pestieau (2000a) study the same model where the strength of the Bismarckian factor is chosen at the constitutional stage.
} 
both in discussions of policy reform and in political economy models (e.g., Casamatta et al., 2000b; Razin et al., 2002), the fact that life expectancy varies has not yet been addressed in positive political models. ${ }^{4}$

I use a model similar to Casamatta et al. (2000b). Voters differ with respect to age and income, but in addition I assume that wealthier individuals live longer. This assumption is supported by numerous empirical studies. For instance, Deaton and Paxson (1999) find a strong positive effect of wealth on life expectancy in the US, and similar findings are obtained by Attanasio and Emerson (2001) for the UK and Reil-Held (2000) for Germany. The implication is that the pension system will be less regressive than it looks on paper. Some authors have indeed found that the positive effect of income on life expectancy can make a pension system regressive. See Coronado, Fullerton and Glass (2000) for the US, Gil and Lopez-Casasnovas (1997) for Spain, and Reil-Held (2000) for Germany.

I study the implication of this assumption for voting outcomes when pension systems can be either Bismarckian or Beveridgean or a combination of the two. Pensions are financed by payroll taxes on labor income. Depending on how much life expectancy increases with income and how tight the link between contributions and benefits is, workers' optimal tax rates may increase or decrease with income. The different voting equilibria which result are characterized. If the optimal tax rate decreases with income, the coalition for high taxes consists of pensioners and poor workers as in Persson and Tabellini (2000). If the individually optimal tax rate increases with income, the coalition for high tax rates instead consists of pensioners and rich workers. It is also possible that the relationship between optimal tax rates and income is U-shaped, in which case an 'ends against the middle' outcome obtains, as in some models of private provision of public goods (Epple and Romano, 1996).

A model similar to the present one is presented by Bethencourt Marrero and Galasso

\footnotetext{
${ }^{4}$ An exception is Bethencourt Marrero and Galasso (2001); see below.
} 
(2001). They argue that social security and public health care are complementary: public health care decreases the longevity differential between rich and poor individuals, which increases the demand for public pensions of the poor. However, in their model, the pension system is assumed to be progressive. By contrast, in my model, public pensions can be either progressive or regressive, depending on the link between benefits and contributions, and the effect of income on longevity.

The paper proceeds as follows. Section 2 introduces the model economy. Section 3 analyzes the voting equilibrium. The last section concludes the paper.

\section{The model}

Suppose at each point in time there are two generations alive, the young (workers) and the old (pensioners). The old population is normalized to one; furthermore, I assume population grows at constant rate $n>0 .{ }^{5}$ Pensioners have no income except for savings and pension benefits. Within the young generation, individuals differ by their income, denoted $y$, and life expectancy. Income is distributed according to the distribution function $F(y)$ with the associated density $f(y)$. Median income is $y^{m}$, where $F\left(y_{m}\right)=\frac{1}{2}$, and average income $\bar{y}=\int y d F(y)$. If the distribution is skewed to the right, average income exceeds median income: $F(\bar{y})>1 / 2$.

Denote individuals' working lives as period 0 , and retirement as period 1 . While everyone reaches retirement, a worker with income $y$ lives for the fraction $\gamma(y)$ of her retirement. The function $\gamma(y)$ is positively increasing, so life expectancy increases with income. This may be thought of as a shortcut to express a more general relationship, where life ex-

\footnotetext{
${ }^{5}$ Of course, population might well shrink in the model as it does in reality in many countries. However, this would put the pensioners in the majority which would make the model uninteresting. This assumption could be relaxed if there were more than two generations.
} 
pectancy is a function of health spending, and richer individuals spend more on health and therefore live longer.

Birth rates are assumed to be identical for all workers so the young population is just an $n$ times larger replica of the old one, and the income distribution remains constant over time.

I assume that the structure of the economy is common knowledge. In particular, voters know the income distribution and the $\gamma(y)$ function, so they know their own as well as everyone else's life expectancy. Note, however, that $\gamma(y)$ can be interpreted as the probability of reaching retirement, in which case uncertainty comes into play.

Preferences of a worker with income $y$ are given by

$$
U_{w}=u\left(c_{0}\right)+\frac{c_{1}}{1+\delta}
$$

where $c_{i}$ refers to consumption in period $i . \delta$ is the common discount rate, which is assumed to equal the given world interest rate $r$. I will assume dynamic efficiency so $r>n$. Utility is increasing and concave in $c_{0}: u^{\prime}>0>u^{\prime \prime}$. The assumption of quasilinear preferences is made for simplicity. ${ }^{6}$ It implies that all income effects are absorbed by old age consumption. While this assumption is not innocuous, all results could be generated with a more general additive utility function under suitable restrictions on risk aversion (see Proposition 3 below).

Pensioners' preferences are similar to workers', but their savings decision is bygone. Thus, preferences of a pensioner with income $y$ are given by

$$
U_{p}=c_{1}
$$

I assume full commitment, that is, once voted on, both taxes and the pension level

\footnotetext{
${ }^{6}$ Persson and Tabellini (2000) and Tabellini (2000) also make this assumption.
} 
remain in place at least for two periods. ${ }^{7}$ A worker's budget constraint is

$$
c_{0}+\frac{c_{1}}{1+r}=(1-\tau) y+\gamma(y) \frac{P}{1+r}
$$

where $\tau$ is the flat payroll tax rate and $P$ the constant pension received during retirement.

Consumers maximize utility by choice of $c_{0}$ and $c_{1}$. Letting $\phi(c)$ denote the inverse function of $u^{\prime}(c)$, optimal working life consumption is $c_{0}^{*}=\phi(1)$, with all income effects absorbed by old age consumption. ${ }^{8}$ For future reference, define the function $v(1) \equiv u(\phi(1))-\phi(1)$.

\section{Voting}

The pension level is given by

$$
P=\beta(\alpha y+(1-\alpha) \bar{y})
$$

where $\beta$ is set to balance the government budget (see below). Note that an individual with income $y$ will receive this pension only for the fraction $\gamma(y)$ of the retirement period. As in Casamatta et al. (2000b), the pension system is assumed to be a convex combination of Beveridgean and Bismarckian. For $\alpha=0$, the pension level depends on average income only and is not related to the individual contribution so it is purely Beveridgean. For $\alpha=1$ pension benefits depend on own contributions only so we have a pure Bismarckian system. Most real world pension systems, however, correspond to neither of the two pure systems but rather to a combination of the two. ${ }^{9}$ The Bismarckian factor is taken to be fixed in

\footnotetext{
${ }^{7}$ Without commitment, young individuals should oppose pensions if they expect the contributions they pay to be lost. Tabellini (2000) has a model without commitment, where the pension level chosen is still positive because of altruism between parents and children. See Galasso and Profeta (2002) for a survey of the issue of commitment.

${ }^{8}$ More precisely, letting $Y$ be an individual's present value of lifetime income, optimal first period consumption is $\max \{0, \min \{Y, \phi(1)\}\}$.

${ }^{9}$ For instance, Germany's pension system is Bismarckian in the sense that benefits are determined by the level of one's own contributions. However, there are some elements which make the system impure, for
} 
the constitution. ${ }^{10}$ If one were to neglect differing life expectancies, the system would be progressive for $\alpha<1$.

In order to characterize interior equilibrium tax rates in a simple way, I assume that tax revenue is given by

$$
T=\left(\tau-(1-\alpha) \tau^{2}\right) \bar{y}
$$

The term $(1-\alpha) \tau^{2}$ is introduced to capture the distortionary effect of payroll taxes. There is a Laffer curve with the revenue maximizing tax rate at $\bar{\tau}=\min \{1,1 /(2(1-\alpha))\}$. Workers do recognize that part of taxation is contributory, so distortions arise only from the non-contributory part of payroll taxes. ${ }^{11}$

The government budget constraint is

$$
(1+n)\left(\tau-(1-\alpha) \tau^{2}\right) \bar{y}=\beta \int(\alpha y+(1-\alpha) \bar{y}) \gamma(y) d F(y)
$$

What will be the pension level chosen by majority voting? Note first that all pensioners prefer the contribution rate which maximizes pensions, $\bar{\tau}$, irrespective of their life expectancy, since they do not contribute anymore to the pension system.

For workers, there is a tradeoff, since high contributions lower net income from working while leading to higher future pensions. Using (2), (3), and (4) in (1), a worker's indirect instance, the recognition of education or child rearing in the benefit formula, even though no contributions were paid for those years.

${ }^{10}$ Casamatta et al. (2000a) derive the choice of $\alpha$ at the constitutional stage. See also Conde-Ruiz and Profeta (2002) who study simultaneous voting on $\tau$ and $\alpha$ and resort to the concept of structure induced equilibrium to resolve the cycling issue in multidimensional voting.

${ }^{11}$ This formulation follows Casamatta et al. (2000b). It would be possible to derive the tax distortion endogenously by adding a labor supply model. Note, however, that even when the system is purely Bismarckian, there is a tax distortion if the economy is dynamically efficient (assuming identical life expectancies), but this distortion is smaller than for $\alpha<1$. For simplicity, I use the formulation in the text. 
utility function can be written

$$
\begin{aligned}
V(\tau, y, \cdot) & =v(1)+(1-\tau) y \\
& +\frac{1+n}{1+r}\left(\tau-(1-\alpha) \tau^{2}\right)(\alpha y+(1-\alpha) \bar{y}) \frac{\gamma(y)}{\Gamma}
\end{aligned}
$$

where

$$
\Gamma \equiv \frac{1}{\bar{y}} \int(\alpha y+(1-\alpha) \bar{y}) \gamma(y) d F(y)=(1-\alpha) \bar{\gamma}+\frac{\alpha}{\bar{y}} \int y \gamma(y) d F(y)
$$

and $\bar{\gamma}=\int \gamma(y) d F(y)$ is average life expectancy.

Since utility is concave in $\tau$, workers' preferences over the contribution rate are single peaked. Therefore, the median voter theorem applies: there exists a unique Condorcet winner which corresponds to the median of the optimal tax rates. It remains to be shown whose optimal tax rate this is - in other words, who the median voter is.

Maximizing (5) with respect to $\tau$ gives voters' optimal tax rates:

Proposition 1 A worker's optimal tax rate is given by:

$$
\begin{aligned}
\tau(y, \cdot) & =\min \{1, \max \{0, \hat{\tau}\}\} \\
\text { where } \hat{\tau} & =\frac{1}{2(1-\alpha)}\left(1-\frac{(1+r) \Gamma y}{(1+n) \gamma(y)(\alpha y+(1-\alpha) \bar{y})}\right) .
\end{aligned}
$$

Whether this tax rate is positive or zero depends on the worker's income, and life expectancy relative to the average of other voters, as well as on the redistributive nature of the pension system.

Consider a pure Beveridgean system. From (7), with $\alpha=0$, a worker's optimal tax rate is positive if and only if

$$
\frac{1+n}{1+r} \frac{\gamma(y)}{\bar{\gamma}}>\frac{y}{\bar{y}}
$$

Suppose that $r=n$. Then a worker can benefit from public pensions in two ways: either if she has lower than average income, or if she has higher than average life expectancy. 
Whether a worker who is richer than average prefers zero pensions depends on the income distribution and the shape of the life expectancy function.

Note that for $\alpha=1, \hat{\tau}$ is not defined. Because the tax distortion vanishes with a pure Bismarckian system and utility is linear in old age consumption, the optimal tax rate will be either zero or one, depending on whether the discounted sum of benefits is smaller or larger than the contribution.

Hence, under a pure Bismarckian system, $\alpha=1$, a worker's optimal tax rate is

$$
\tau(y, \cdot)=\left\{\begin{array}{lll}
0 & \text { if } & (1+n) \gamma(y)<(1+r) \frac{\hat{y}}{\bar{y}} \\
\tau \in[0,1] & \text { if } & (1+n) \gamma(y)=(1+r) \frac{\hat{y}}{\bar{y}} \\
1 & \text { if } & (1+n) \gamma(y)>(1+r) \frac{\hat{y}}{\bar{y}}
\end{array},\right.
$$

where $\hat{y} \equiv \int y \gamma(y) d F(y)$ is life expectancy weighted average income.

Under the Bismarckian system, if $r=n$, for identical life expectancies each individual would receive a pension which just equals her contributions. With differing life expectancies, whether a worker benefits from the pension system depends on her life expectancy and the relation of life expectancy weighted average income to average income.

To study how optimal tax rates change with income, define the income elasticity of $\gamma(y)$ :

$$
\epsilon \equiv \gamma^{\prime}(y) \frac{y}{\gamma(y)}
$$

The following result characterizes how the optimal tax rate changes with income. ${ }^{12}$

Proposition 2 A worker's optimal tax rate satisfies:

$$
\frac{\partial \tau(y, \cdot)}{\partial y} \gtreqless 0 \Leftrightarrow \epsilon \gtreqless \frac{(1-\alpha) \bar{y}}{\alpha y+(1-\alpha) \bar{y}} .
$$

Proof. Differentiating (7) and simplifying gives

$$
\frac{\partial \tau(y, \cdot)}{\partial y}=\frac{(1+r) \Gamma\left[y \gamma^{\prime}(y)(\alpha y+(1-\alpha) \bar{y})-(1-\alpha) \bar{y} \gamma(y)\right]}{2(1-\alpha)(1+n)[(\alpha y+(1-\alpha) \bar{y}) \gamma(y)]^{2}}
$$

\footnotetext{
${ }^{12}$ Strictly speaking, of course, the result only holds for individuals with an interior optimal tax rate.
} 
Solving the inequality on the left of (8) for $\gamma^{\prime}(y)$ and using the definition of $\epsilon$ gives the result.

If $\epsilon=0$, the optimal tax rate is nonincreasing in income; it is strictly decreasing for $\alpha<1$. If life expectancy were the same for all individuals, the pension system would be progressive unless it is purely Bismarckian. However, since life expectancy increases with income, the system might be regressive even if it is less than fully Bismarckian.

The rightmost expression in (8) is decreasing in $\alpha$ and increasing in $\bar{y}$. Thus, the optimal tax rate is more likely to increase with income, the more Bismarckian the pension system, and the lower average income. Assuming $\epsilon$ to be constant, it is also more likely the higher a voter's income (unless the system is purely Beveridgean), and the larger the income elasticity of life expectancy.

Using the extreme cases of $\alpha=0$ and $\alpha=1$ in (8) gives the two polar cases:

Corollary 1 Under a pure Bismarckian system, the individually optimal tax rate increases with income if and only if $\epsilon>0$, which holds by assumption. Under a pure Beveridgean system, the individually optimal tax rate increases with income if and only if $\epsilon>1$.

The Bismarckian system is proportional if life expectancy is identical for all income earners, and regressive if longevity increases with income. By contrast, the Beveridgean system is regressive only if the income elasticity of longevity is larger than one.

Before proceeding, a note on the generality of the results may be in order. Suppose utility is of the form $U=u\left(c_{0}\right)+u\left(c_{1}\right) /(1+\delta)$. Casamatta et al. (2000b) show in a model with homogeneous life expectancy that optimal tax rates increase with income if $\rho<1$, where $\rho$ is the (constant) coefficient of relative risk aversion (which equals the elasticity of intertemporal substitution). In the present model, the following result holds. 
Proposition 3 Let $U=u\left(c_{0}\right)+\frac{u\left(c_{1}\right)}{1+\delta}$ and $T=\tau \bar{y}$. With a Bismarckian system, optimal tax rates increase with income if $\epsilon>0$. In a Beveridgean system, the optimal tax rate increases with income if $\epsilon>\rho-1$.

Proof. See Appendix.

Hence, the results stated below can be generated with a general additive utility function under suitable assumptions on risk aversion. The next result characterizes possible properties of the voting equilibrium.

Proposition 4 (i) If the optimal tax rate of workers is decreasing in income, the equilibrium tax rate, $\tau^{*}$, is that of the worker with income $y_{l}$, where $F\left(y_{l}\right)=\frac{n}{2(1+n)}<\frac{1}{2}$. (ii) If the optimal tax rate is increasing in income, the decisive voter has income $y_{h}>y_{l}$, where $F\left(y_{h}\right)=\frac{2+n}{2(1+n)}>\frac{1}{2}$. (iii) If the relationship between optimal tax rates and income is $U$ shaped, there is a pair of decisive voters with incomes $y_{1}<y_{2}$, where $F\left(y_{2}\right)-F\left(y_{1}\right)=\frac{2+n}{2(1+n)}$.

Proof. In case (i), the coalition favoring high tax rates consists of pensioners and workers with income $y<y_{l}$. This must be half the population in equilibrium. Since pensioners have mass one, workers with income below $y$ have mass $(1+n) F(y)$, and the total population has mass $2+n$, this implies that $1+(1+n) F\left(y_{l}\right)=\frac{1}{2}(2+n)$. In case (ii), those favoring low taxes are workers with $y<y_{h}$, which again must be half the population, $(1+n) F\left(y_{h}\right)=\frac{1}{2}(2+n)$. In case (iii), the coalition preferring low taxes consists of workers with incomes $y_{1}<y<y_{2}$, where $(1+n)\left(F\left(y_{2}\right)-F\left(y_{1}\right)\right)=\frac{1}{2}(2+n)$.

The proposition shows that several outcomes are possible. Case (i) is the same as in Persson and Tabellini (2000). Redistribution is from young to old and rich to poor. Since all the old prefer maximum pensions, the decisive voter is a young voter with income below the median. Conversely, in case (ii) workers' optimal tax rates increase with income, so 


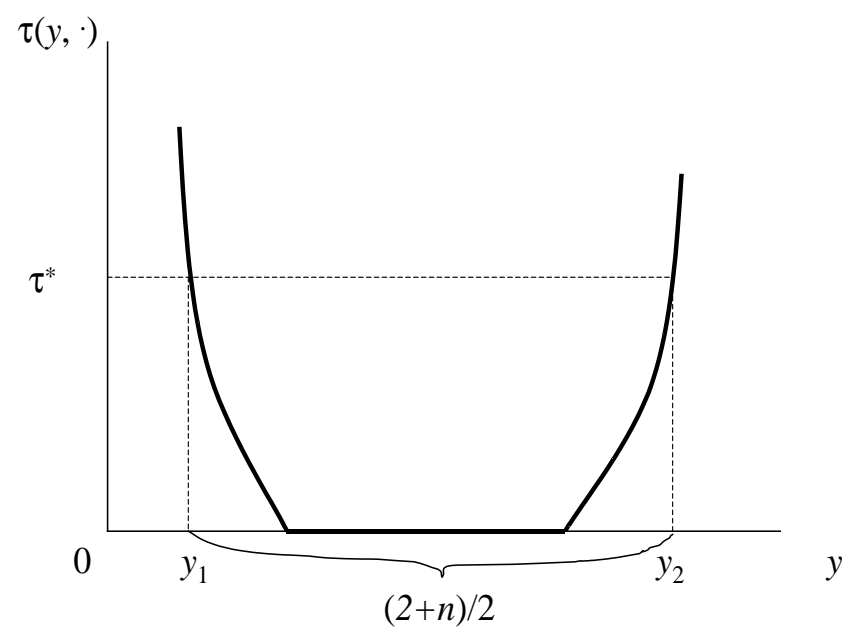

Figure 1: Optimal tax rates in case (iii).

the coalition of high tax rate supporters consists of pensioners and rich workers, with the decisive voter's income above the median. In this case, intragenerational redistribution is from poor to rich, as demonstrated empirically, for instance, by Coronado et al. (2000). In case (iii) the relationship between income and optimal tax rate is non-monotonic. There are two decisive voters. One has income above and one below the median (see Figure 1). ${ }^{13}$ In this case, intragenerational redistribution is from the middle class to the poor (who pay low taxes) and rich (who outlive the middle class sufficiently to benefit from social security).

\section{Conclusion}

Public pension systems redistribute across and, possibly within generations. The latter type of redistribution comes about because individual pension benefits are not perfectly

\footnotetext{
${ }^{13}$ In the case of dynamic efficiency, there must be some individuals who prefer a zero tax rate, whereas in a dynamically inefficient economy, all young individuals may benefit from the pension system (Aaron, 1966).
} 
tied down by contributions. Since lower income individuals usually contribute less for a similar pension than high income individuals, pension systems may be progressive. However, high income individuals also live longer. Hence, the system may even be regressive if the longer life expectancy more than outweighs the higher contributions. There is growing empirical evidence that real world pension systems may actually be regressive when individual heterogeneity of life expectancy is taken into account (e.g., Coronado et al., 2000; Gil and Lopez-Casasnovas, 1997; Reil-Held, 2000). It is interesting to note that this result can be found in more Bismarckian systems such as Germany, but also in more Beveridgean systems such as the US.

The paper shows that this may have important implications for voting outcomes. If life expectancy were identical for all individuals and the pension system Beveridgean, the coalition for high pensions would consist of pensioners and poor workers. If the system is sufficiently Bismarckian and life expectancy sufficiently income elastic, this coalition may instead consist of pensioners and the rich workers. Other possible outcomes have an 'ends against the middle' property as in the public provision of private goods (Epple and Romano, 1996). In particular, there may be equilibria where within the young generation the pensions system redistributes from the middle class to the rich and poor. This is, in a sense, 'Director's law' stood on its head.

The model also has implications for the empirical study of pension systems. If pensions were to redistribute from rich to poor, one would expect more income inequality (appropriately measured) to lead to higher pension levels. The evidence on this is, however, mixed (see Lindert, 1996; Perotti, 1996; Tabellini, 2000; Razin et al., 2002). The model presented here might partially account for this. In fact, if the pension system is sufficiently Bismarckian and life expectancy increases with income, more inequality may lead to lower pensions. One possible interpretation of this mixed evidence is data problems or omitted variables. Another is that in cross country studies, in some countries the pension level may 
be positively and in others negatively influenced by inequality, depending on the strength of the Bismarckian factor and the relationship between life expectancy and income. Future empirical research may tackle these questions.

\section{Appendix}

\section{Proof of Proposition 3}

The individual problem is

$$
\begin{array}{ll}
\max & u\left(c_{0}\right)+\frac{u\left(c_{1}\right)}{1+\delta} \\
\text { s.t. } & c_{0}=(1-\tau) y-s \\
& c_{1}=(1+r) s+\frac{\gamma(y)}{\Gamma}(1+n)(\alpha y+(1-\alpha) \bar{y}) .
\end{array}
$$

The first order condition for the individual savings decision is

$$
-u_{0}^{\prime}+u_{1}^{\prime} \leqq 0
$$

where $u_{i}^{\prime} \equiv u^{\prime}\left(c_{i}\right)$ for $i=0,1$. The first order condition for an interior solution for the optimal tax rate is

$$
\phi=-y u_{1}^{\prime}+\frac{\gamma(y)}{\Gamma} \frac{1+n}{1+r}(\alpha y+(1-\alpha) \bar{y}) u_{2}^{\prime}=0
$$

From (9) and (10), an individual who votes for a positive tax rate will not save privately.

Differentiating (10) with respect to $y$ gives

$$
\begin{array}{r}
\phi_{y}=-y u_{1}^{\prime}-(1-\tau) y u_{1}^{\prime \prime}+\frac{\gamma(y)}{\Gamma} \frac{1+n}{1+r}\left(\alpha u_{2}^{\prime}+(\alpha y+(1-\alpha) \bar{y})(1+n) \tau \alpha\right) \\
+\frac{1+n}{1+r}(\alpha y+(1-\alpha) \bar{y}) u_{2}^{\prime} \frac{\gamma^{\prime}(y)}{\Gamma} .
\end{array}
$$

Define $\rho_{i}=\rho \equiv-c_{i} u_{i}^{\prime \prime} / u_{i}^{\prime}$, where $c_{0}=(1-\tau) y$ and $c_{1}=\frac{\gamma(y)}{\Gamma}(1+n) \tau(\alpha y+(1-\alpha) \bar{y})$ for an individual who prefers a positive tax rate. Using the definition of $\rho$ and (10) gives

$$
\phi_{y}=\frac{\gamma(y)}{\Gamma} \frac{1+n}{1+r}\left((1-\alpha) \frac{\bar{y}}{y}(1-\rho)+(\alpha y+(1-\alpha) \bar{y}) \frac{\gamma^{\prime}(y)}{\gamma(y)}\right) .
$$


Substituting $\alpha=0$ or $\alpha=1$ into (11) and simplifying gives the result.

\section{References}

Aaron, H. (1966). The social insurance paradox, Canadian Journal of Economics and Political Science 32: 371-374.

Attanasio, O. and Emerson, C. (2001). Differential mortality in the UK, IFS working paper $01 / 16$

Bethencourt Marrero, C. and Galasso, V. (2001). On the political complementarity between health care and social security, CEPR discussion paper no. 2788.

Boadway, R. W. and Wildasin, D. E. (1989). A median voter model of social security, International Economic Review 30: 307-328.

Browning, E. K. (1975). Why the social insurance budget is too large in a democracy, Economic Inquiry 13: 373-388.

Casamatta, G., Crémer, H. and Pestieau, P. (2000a). On the political sustainability of redistributive social insurance systems, Journal of Public Economics 75: 341-364.

Casamatta, G., Crémer, H. and Pestieau, P. (2000b). The political economy of social security, Scandinavian Journal of Economics 102: 502-522.

Conde-Ruiz, J. I. and Profeta, P. (2002). What social security: Beveridgean or bismarckian, mimeo.

Coronado, J. L., Fullerton, D. and Glass, T. (2000). The progressivity of social security, NBER working paper 7520 . 
Deaton, A. and Paxson, C. (1999). Mortality, education, income and income inequality among american cohorts, NBER working paper 7141.

Epple, D. and Romano, R. E. (1996). Ends against the middle: Determining public service provision when there are private alternatives, Journal of Public Economics 62: 297325.

Galasso, V. and Profeta, P. (2002). The political economy of social security: A survey, European Journal of Political Economy 18: 1-29.

Gil, J. and Lopez-Casasnovas, G. (1997). Life-time redistribution effects of the spanish public pension system, University Pompeu Fabra working paper.

Lindert, P. H. (1996). What limits social spending?, Explorations in Economic History 33: $1-34$.

Mulligan, C. B. and Sala-i-Martin, X. (1999). Gerontocracy, retirement, and social security, Mimeo.

Perotti, E. C. (1996). Growth, income distribution and democracy: What the data say, Journal of Economic Growth 1: 149-188.

Persson, T. and Tabellini, G. (2000). Political Economics, MIT Press, Cambridge, MA.

Razin, A., Sadka, E. and Swagel, P. (2002). The aging population and the size of the welfare state, Journal of Political Economy 110: 900-918.

Reil-Held, A. (2000). Einkommen und Sterblichkeit in Deutschland: Leben Reiche länger?, Discussion paper 00-14, SFB 504, Mannheim.

Tabellini, G. (2000). A positive theory of social security, Scandinavian Journal of Economics 102: 523-545. 